\title{
Margem de Contribuição como Instrumento de Gestão: Aplicação em uma indústria de extração e beneficiamento de minérios
}

Doutorado em andamento em Ciências Contábeis pela Universidade do Vale do Rio dos

Sinos - UNISINOS

Professor da Faculdade Dom Alberto Rua Ramiro Barcellos, 892. Centro. Santa Cruz do Sul/RS. CEP: 96810-050 E-mail: daniel.bartz@domalberto.edu.br

Ingrid Pereira Fanfa

Graduação em Ciências Contábeis pela Faculdade Dom Alberto Ramiro Barcellos, 892. Centro. Santa Cruz do Sul/RS. CEP: 96810-050

E-mail: ingridfanfa@domalberto.edu.br

Vinícius Costa da Silva Zonatto

Doutorado em andamento em Ciências Contábeis e Administração pela Universidade

Regional de Blumenau - FURB

Professor da Faculdade Dom Alberto

Ramiro Barcellos, 892. Centro. Santa Cruz do Sul/RS. CEP: 96810-050

E-mail: viniciuszonatto@gmail.com

Rodrigo da Silveira Kappel

Doutorado em andamento em Ciências Contábeis pela Universidade do Vale do Rio dos Sinos - UNISINOS

Professor da Faculdade Dom Alberto Ramiro Barcellos, 892. Centro. Santa Cruz do Sul/RS. CEP: 96810-050 E-mail: rodrigokappel@domalberto.edu.br

\section{RESUMO}

O estudo tem como tema a contabilidade de custos, mais especificamente a análise da utilização da margem de contribuição como um instrumento de gestão. O objetivo central da pesquisa é analisar a margem de contribuição dos produtos fabricados por uma empresa que desenvolve atividades ligadas à extração e ao beneficiamento de minérios e sua contribuição para a tomada de decisão, utilizando-se o método de custeio variável. A pesquisa caracteriza-se como de natureza exploratória e descritiva, com abordagem qualitativa e quantitativa dos dados, realizada por meio da análise de documentos. Para tanto, buscou-se a identificação dos elementos de custos componentes dos produtos e demais informações necessárias à determinação da margem de contribuição. Os principais resultados encontrados na pesquisa mostram que todos os produtos fabricados pela organização em estudo apresentam significativa margem de contribuição, porém a empresa pesquisada não a utiliza como um 
Margem de contribuição como Instrumento de Gestão: Aplicação em uma indústria de extração e beneficiamento de minérios.

Daniel Bartz, Ingrid Pereira Fanfa, Vinícius Costa da Silva Zonatto, Rodrigo da Silveira Kappel

instrumento de suporte ao processo decisório. Neste sentido, pôde-se concluir que a utilização da margem de contribuição para fins de apoio ao processo decisório poderá contribuir com a organização para a maximização dos seus resultados, uma vez que tal análise permite ao gestor avaliar o detalhamento dos custos diretos de fabricação por produto e sua rentabilidade, contribuindo na formação do preço de venda.

Palavras-chave: Gestão de Custos. Margem de Contribuição. Processo Decisório.

\section{Contribution Margin as a Management Tool: Application in an industry of extraction and processing of minerals}

\section{ABSTRACT}

The study is subject to cost accounting, specifically the analysis of the use of the contribution margin as a management tool. The central aim of the research is to analyze the contribution margin of the products manufactured by a company that develops activities related to the extraction and processing of ore and its contribution to decisionmaking, using the variable costing method. The methodology used in the research is characterized as a case study, exploratory and descriptive study, qualitative and quantitative data, conducted through document analysis. Therefore, we sought to identify the elements of component costs of products and other information necessary for the study of the contribution margin. The main findings in the study show that all products manufactured by the organization under study have significant contribution margin. It was found that the company does not use researched analysis of the contribution margin as a tool to support decision making. In this sense, after the completion of the proposed study, we concluded that the use of the contribution margin for purposes of policy making can contribute to the organization to maximize the company's results, since such analysis allows the manager to assess the breakdown of direct costs for manufacturing and product profitability, improving training of the sales price.

Key-words: Cost Management. Contribution Margin. Decision Making.

\section{INTRODUÇÃO}

Gerenciar uma empresa no atual cenário de negócios requer que os gestores tenham conhecimento do ambiente no qual atuam e para tanto precisam monitorar constantemente fatores externos e internos. No meio ambiente externo uma variável que impacta a gestão das empresas é o fato dos clientes estarem se tornando cada vez 
Margem de contribuição como Instrumento de Gestão: Aplicação em uma indústria de extração e beneficiamento de minérios.

Daniel Bartz, Ingrid Pereira Fanfa, Vinícius Costa da Silva Zonatto, Rodrigo da Silveira Kappel

mais exigentes em relação à qualidade e preço, tornando o mercado bem mais competitivo, com reflexos nas práticas de gestão das organizações.

Frente a esse cenário, os gestores necessitam estar preparados para suplantar as dificuldades e/ou aproveitar as oportunidades, e para isso um bom sistema de informações é requisito essencial para suportar o processo decisório. Assim, no âmbito interno, um dos instrumentos de grande importância para a gestão organizacional é a Contabilidade, pois de acordo com ludícibus, Martins e Gelbcke (2006, p. 48), "a contabilidade é, objetivamente, um sistema de informação e avaliação destinado a prover seus usuários com demonstrações e análises de natureza econômica, financeira, física e de produtividade, com relação à entidade objeto de contabilização".

Em seu contexto, especialmente nas organizações industriais, um dos aspectos mais essenciais e que pode influenciar diretamente seus resultados são os custos. Conforme Leone (2000, p. 22), a contabilidade de custos se refere às "atividades de coleta e fornecimento de informações para as necessidades de tomada de decisão de todos os tipos, desde as relacionadas com operações repetitivas até as de natureza estratégica". Isso significa que, além do aspecto operacional, há um direcionamento para a gestão de custos com foco estratégico, de modo a proporcionar a manutenção do nível de competitividade da empresa.

Assim, a estruturação do sistema de controle e análise de custos, bem como sua sofisticação técnica e sua complexidade, depende de qual o nível de informação é necessário reportar aos gestores e dos recursos disponíveis. Para que se atenda a contento a geração de informações de custos, pressupõe-se a existência de uma contabilidade que registre os itens de custos adequadamente. Isso requer, por exemplo, a segregação dos custos e despesas fabris em variáveis e fixos, que dependendo de fatores organizacionais como tamanho, complexidade, mercado de atuação, nem sempre é perfeitamente viável e/ou factível.

Uma das informações possíveis de ser extraída da contabilidade de custos está relacionada à análise da margem de contribuição dos produtos fabricados por uma organização. A margem de contribuição pode ser compreendida como a receita subtraída de todos os custos que variam com relação ao nível de atividades da 
empresa (HORNGREN; FOSTER; DATAR, 2004). Segundo Carvalho Jr. et al. (2009), a análise da margem de contribuição é um instrumento de gestão que serve como ferramenta estratégica para avaliação da atividade operacional das organizações. A partir desta, torna-se possível detalhar os custos diretos de produção, bem como avaliar a rentabilidade dos produtos.

Nessa direção, este estudo tem como propósito central analisar a margem de contribuição de uma empresa que desenvolve atividades ligadas à extração e ao beneficiamento de minérios e inferir sua importância para a tomada de decisão, utilizando-se o método de custeio variável. Para tanto, de forma mais específica buscase: discutir os principais conceitos inerentes ao estudo da margem de contribuição; identificar os elementos de custos pertinentes à atividade de extração e beneficiamento de minerais; apurar a margem de contribuição dos produtos estudados; e, analisar a importância da margem de contribuição para a tomada de decisão na empresa. A pesquisa limita-se a estudar exclusivamente a margem de contribuição dos produtos da empresa, com enfoque gerencial. Não faz parte do escopo do estudo examinar o preço de venda, que, para fins da apuração da margem de contribuição, foi identificado junto à área comercial da empresa pesquisada.

Visto que a gestão de custos pode contribuir para uma melhor análise, subsidiando o processo decisório, acredita-se que a justificativa e contribuição desse estudo estão relacionadas à: [1] evidenciação de uma aplicação prática que permita reflexões teóricas acerca da validade da margem de contribuição para fins gerenciais e ao mesmo tempo reflita a realidade empresarial; [2] servir de material motivador para que outros estudos dessa ordem sejam realizados e levem adiante discussões correlatas; e, [3] contribuir para a melhoria dos processos de gestão da empresa estudada. 
Margem de contribuição como Instrumento de Gestão: Aplicação em uma indústria de extração e beneficiamento de minérios. Daniel Bartz, Ingrid Pereira Fanfa, Vinícius Costa da Silva Zonatto, Rodrigo da Silveira Kappel

\section{FUNDAMENTAÇÃO TEÓRICA}

\subsection{Métodos de custeio}

Ao expor sobre os sistemas utilizados pela contabilidade de custos, Leone (2001, p. 32) explica que ela "emprega vários sistemas que representam conjuntos de critérios, convenções, procedimentos e registros que interagem, de modo coordenado, no sentido de atender a determinadas finalidades". Nesse sentido, surge a questão dos diferentes métodos de custeio passíveis de utilização, dentre os quais, destacam-se: custeio por absorção, custeio direto ou variável, custeio ABC (Custeio Baseado em Atividades) e UEP (Unidade Esforço de Produção).

Para Megliorini (2007), os diferentes métodos de custeio são adotados de acordo com a necessidade de cada empresa, podendo ser classificados como métodos de custeio tradicionais e contemporâneos. É oportuno destacar que não se tem aqui a pretensão de discutir detalhadamente os métodos de custeio, mas sim, apresentar uma abordagem sucinta de alguns deles, com um enfoque posterior mais denso sobre o custeio variável por relacionar-se diretamente ao tema do estudo.

O autor menciona que os métodos de custeio tradicionais são aqueles que têm como foco principal a apuração do custo dos produtos, e que os custeios tradicionais abrangem o custeio por absorção e o custeio variável. O custeio por absorção é o método mais tradicional, onde todos os custos de produção são apropriados aos produtos do período. No método de custeio variável, os custos fixos não são apropriados aos produtos, sendo considerados como despesas do período. Nesse método utilizam-se somente os custos variáveis do produto, sejam diretos ou indiretos. Horngren (2000, p. 211) define custeio variável como o "método de custeio de estoques em que todos os custos de fabricação variáveis são considerados custos inventariáveis".

Megliorini (2007) complementa sua análise, afirmando que o método de custeio variável é estruturado a atender à administração das empresas, pois permite a visualização da margem de contribuição de cada produto, o que possibilita utilizá-la como instrumento gerencial de apoio ao processo decisório. A decisão de produzir ou 
Margem de contribuição como Instrumento de Gestão: Aplicação em uma indústria de extração e beneficiamento de minérios.

Daniel Bartz, Ingrid Pereira Fanfa, Vinícius Costa da Silva Zonatto, Rodrigo da Silveira Kappel

não produzir, manter ou retirar algum produto de seu mix, fechar ou não fechar alguma filial, se tomada com base no custeio variável e sob o enfoque da margem de contribuição, certamente terá um grau de assertividade maior do que se fosse tomada com base no custeio por absorção e baseada apenas nos demonstrativos contábeis.

Por sua vez, em relação aos métodos contemporâneos, Wernke (2004) descreve-os como uma nova abordagem de gestão de custos, como o custeio UEP e o $A B C$, que permite melhor visualização dos custos por meio da análise das atividades executadas na empresa e suas respectivas relações com os produtos.

O método UEP baseia-se na constância em relações entre potenciais produtivos. Os procedimentos propostos para mensuração das perdas necessitam ainda que duas outras relações se mantenham constantes: entre potenciais fixos e variáveis e efetivos e adicionais. Para Bornia (2002), a implantação do método UEP necessita de cinco procedimentos básicos: [1] divisão da fábrica em postos operativos; [2] cálculo dos índices de custos; [3] escolha do produto base; [4] cálculo dos potenciais produtivos; [5] determinação dos equivalentes dos produtos.

Já o método $A B C$, de acordo com Martins (2003, p. 87), "é uma metodologia de custeio que procura reduzir sensivelmente as distorções provocadas pelo rateio arbitrário dos custos indiretos". O ABC tem como fundamento básico a busca do princípio da causa, ou seja, procura identificar de forma clara, por meio de rastreamento, o agente causador do custo para lhe imputar o valor. A idéia básica é atribuir primeiramente os custos às atividades e posteriormente atribuir custos das atividades aos produtos.

Como a pesquisa está direcionada à análise da margem de contribuição, aborda-se na sequência o custeio variável e a utilização da margem de contribuição como instrumento de apoio ao processo decisório, discutindo-se aspectos essenciais ao seu entendimento e aplicabilidade. 
Margem de contribuição como Instrumento de Gestão: Aplicação em uma indústria de extração e beneficiamento de minérios. Daniel Bartz, Ingrid Pereira Fanfa, Vinícius Costa da Silva Zonatto, Rodrigo da Silveira Kappel

\subsection{O custeio variável e a utilização da margem de contribuição para fins de suporte ao processo decisório}

Cavenaghi (1996, p. 7) entende-se que a área de produção tem a missão de produzir produtos e serviços demandados pelo mercado, nas condições de quantidade, qualidade e produtividade, definidas pelas políticas da empresa, desejando obter certo resultado econômico. Para que tal missão possa ser cumprida adequadamente, o modelo de informação da área de produção necessita ter integração com todas as operações e modelado de forma a captar os dados necessários, transformando-os em informações úteis e tempestivas para a tomada de decisão.

Com esse direcionamento, Leone (2001) afirma que a utilização dos custos para tomada de decisão determina o rumo de ações que provocará alterações sobre os lucros da empresa em curto e longo prazo. Megliorini (2003) destaca que é importante para a tomada de decisões saber a maneira de identificar, mensurar e informar os custos dos produtos ou serviços. Para o autor, a contabilidade de custos têm como objetivo conhecer os custos dos produtos, para avaliar os estoques e apurar o resultado.

Nesta perspectiva, ludícibus (2000) entende que a contabilidade de custos está preocupada com apuração do resultado, ou seja, identificar o lucro de forma mais adequada. No mesmo sentido, Martins (2003) defende que independentemente da estratégia de custo adotada pela empresa, o mercado é o grande responsável pela fixação dos preços, e não os custos dos produtos, e por isso a boa gestão de custos tem seu importante objetivo na maximização dos lucros. Para o autor, torna-se essencial conhecer o custo do produto para definir seu preço de venda, mas essa informação por si só não é suficiente. É preciso também estar atento a fatores externos à empresa e que acabam por influenciar sua gestão em termos de custos.

Nesse contexto, quando se trata de custos para fins gerenciais, a análise da margem de contribuição é bastante apreciada. Sua abordagem pressupõe a utilização do custeio variável, pois o custo variável subtraído da receita proveniente da venda do produto gera uma margem de contribuição. Para Hansen e Mowen (2001), a análise pelo custeio variável é eficiente para o planejamento e tomada de decisão. Conforme 
Margem de contribuição como Instrumento de Gestão: Aplicação em uma indústria de extração e beneficiamento de minérios. Daniel Bartz, Ingrid Pereira Fanfa, Vinícius Costa da Silva Zonatto, Rodrigo da Silveira Kappel

Bruni e Famá (2004), o custeio variável é sugerido para fins decisórios devido a não haver rateios de custos fixos ou indiretos, o que não provoca distorções no custo dos produtos.

Entretanto, alguns autores enfatizam que a tomada de decisões a partir do custeio variável e da margem de contribuição é mais adequada para o curto prazo (SANTOS, 1987; LEONE, 1997; SHANK; GOVIDARAJAN, 1997; HENDRIKSEN, 1999; HORNGREN, 2000; MAHER, 2001). A possibilidade da direção da empresa tomar decisões que provoquem alteração na estrutura de custos e as variações do preço de venda devido a fatores de mercado, que provocam alterações na margem de contribuição, são argumentos citados para corroborar tal afirmativa.

Outra questão a ser considerada é que a avaliação de produtos pela margem de contribuição necessita de um maior aprofundamento para tornar-se amplamente válida num cenário de longo prazo. Um elemento a ser avaliado é a projeção do fluxo de caixa a ser gerado pelo produto em períodos futuros, demonstrando a viabilidade de manutenção do seu volume de vendas, evitando tomar decisões equivocadas a partir de um produto com alta margem de contribuição, mas sem estimar seu potencial de vendas.

A análise da margem de contribuição é relativamente simples, pois visa a identificar o que sobrou da receita de vendas depois de deduzidos os custos e as despesas variáveis de fabricação. $O$ valor resultante irá contribuir para a cobertura dos custos fixos e para a formação do lucro. Teoricamente os produtos que gerarem as maiores margens de contribuição são os que propiciam um lucro maior.

A margem de contribuição pode ser calculada de forma unitária ou total. A margem de contribuição unitária "é a diferença entre a receita e o custo variável de cada produto; é o valor que cada unidade efetivamente traz à empresa de sobra entre sua receita e o custo que de fato provocou e the pode ser imputado sem erro" conforme explica Martins (1998, p. 195). Por sua vez, a margem de contribuição total considera o volume total vendido.

Um elemento a ser considerado, quando analisada a margem de contribuição, é a existência de fatores restritivos dentro do sistema produtivo. Martins (2003, p. 209) 
Margem de contribuição como Instrumento de Gestão: Aplicação em uma indústria de extração e beneficiamento de minérios.

Daniel Bartz, Ingrid Pereira Fanfa, Vinícius Costa da Silva Zonatto, Rodrigo da Silveira Kappel

observa que "[...] interessa o produto que produz maior margem de contribuição por unidade, mas, se existir interessa o que produz maior margem de contribuição pelo fator de restrição da capacidade". O estudo das restrições em um sistema é importante para otimizar os lucros da empresa, uma vez que frente a uma limitação na produção, a empresa tem de decidir qual produto priorizar em detrimento de outro. O gestor deve ter uma leitura muito atenta de sua estrutura interna a fim de constatar corretamente possíveis fatores restritivos e tomar as medidas gerenciais adequadas para minimizar o impacto nos resultados.

\section{METODOLOGIA DA PESQUISA}

A pesquisa é caracterizada como de natureza exploratória e descritiva, realizada por meio de análise de documentos, com abordagem qualitativa e quantitativa dos dados. A pesquisa é exploratória, pois visa a identificar elementos de uma realidade empresarial até então pouco conhecida e, também, por pretender levantar questões para futuros estudos. De acordo com Gil (1996), propiciar maior familiaridade com o problema, deixando-o mais explícito, é o objetivo da pesquisa exploratória. Por sua vez, a pesquisa também pode ser caracterizada como descritiva, por enfatizar a descrição de como ocorre o evento, porém sem interferir nos acontecimentos.

A seleção da empresa investigada se deu por acessibilidade e conveniência. A empresa pesquisada é uma organização industrial que atua nas atividades de extração e beneficiamento de minérios e não utiliza a análise da margem de contribuição como um instrumento de suporte ao processo decisório. Apresentou-se aos gestores da organização a proposta de pesquisa, bem como se demonstrou as oportunidades de melhoria que podem ser obtidas nos processos de gestão, a partir da utilização da análise da margem de contribuição. De posse da autorização recebida pelos gestores, procedeu-se a coleta e análise dos dados necessários à realização das inferências sobre o objeto de estudo.

Os dados foram coletados por meio da análise de documentos e relatórios da área contábil e de custos, bem como de outros documentos relacionados ao objeto do 
Margem de contribuição como Instrumento de Gestão: Aplicação em uma indústria de extração e beneficiamento de minérios.

Daniel Bartz, Ingrid Pereira Fanfa, Vinícius Costa da Silva Zonatto, Rodrigo da Silveira Kappel

estudo, que foram disponibilizados pela organização. Também houve contato direto com os responsáveis da empresa envolvidos no processo de controle de custos, os quais foram selecionados por serem considerados informantes chave do objeto estudado. Esse contato pode ser caracterizado como uma entrevista não estruturada, com o objetivo de complementar as informações coletadas por meio da consulta documental de modo a propiciar maior confiabilidade das informações analisadas.

De posse destas informações, procedeu-se a análise dos dados. As informações coletadas na pesquisa foram tabuladas em planilhas eletrônicas. Para a análise dos dados o problema foi abordado, inicialmente, de forma qualitativa. Raupp e Beuren (2003, p. 92) destacam que "na pesquisa qualitativa concebem-se análises mais profundas em relação ao fenômeno que está sendo estudado". A seguir, procedeu-se a investigação quantitativa dos dados, no que diz respeito à identificação dos custos e do cálculo da margem de contribuição dos produtos. Os resultados desta análise são apresentados a seguir.

\section{APRESENTAÇÃO E ANÁLISE DOS DADOS}

\subsection{Caracterização da empresa e dos produtos pesquisados}

A empresa pesquisada é uma indústria de extração e beneficiamento de minerais, mais especificamente o caulim. Está situada no interior do Estado do Rio Grande do Sul, aonde se localizam sua área administrativa e industrial. A unidade em análise é uma filial, estando a matriz localizada em outro município. As instalações da empresa são próprias, porém alguns locais de extração do caulim situam-se em propriedades de terceiros. Todos os cuidados legais para a extração do caulim são observados pela empresa, que possui todas as licenças ambientais emitidas pelos órgãos competentes.

A indústria é caracterizada como uma empresa de porte médio, com estrutura física composta de seis galpões, sendo dois para depósito dos materiais, três galpões para a produção e um para a oficina de manutenção de máquinas e equipamentos. Possui três salas, que compreendem escritório administrativo, laboratório e alojamento. 
Margem de contribuição como Instrumento de Gestão: Aplicação em uma indústria de extração e beneficiamento de minérios.

Daniel Bartz, Ingrid Pereira Fanfa, Vinícius Costa da Silva Zonatto, Rodrigo da Silveira Kappel

A empresa possui uma retroescavadeira, uma carregadeira de uso da fábrica, duas caçambas basculantes e uma escavadeira de esteira usada na extração de matériaprima das jazidas. A área de produção conta com um secador movido à energia elétrica e a lenha, e quatro moinhos movidos à energia elétrica. Para atuar nas atividades administrativas e produtivas a empresa conta com um grupo de quinze colaboradores, distribuídos nas seguintes áreas: oito na produção, três na mineração, um na manutenção, dois na administração e um na área comercial.

O produto comercializado pela empresa é o caulim, que é um material refratário sílico aluminoso (classe S.A.2). É uma rocha composta de material argiloso de cor branca ou tonalidade clara que pode ser empregado para os mais diversos fins, como na indústria cerâmica, de pisos e de azulejos. É também utilizado como carga em borrachas, nos fertilizantes, como veículo diluente dos agentes tóxicos nos pesticidas e inseticidas, em pigmentos para tintas e, até mesmo, em ração animal. $\mathrm{Na}$ empresa pesquisada, são comercializados os seguintes tipos de caulim: caulim rosa "in natura", caulim rosa moído seco, caulim rosa extra fino, caulim branco "in natura", caulim branco moído seco, caulim branco extra fino, geralmente fornecidos em sacos de papel ou big bags.

A empresa também trabalha com várias argilas, como a argila cinza "in natura", argila marrom "in natura" e argila preta "in natura", que são vendidas a granel. As argilas são extremamente finas e plásticas, usadas em louças, porcelanas, azulejos e refratários, etc. O volume de venda é relativamente baixo, mas a qualidade do produto é excelente, pois é um produto que não passa por nenhum processo químico em seu processamento, o que não gera riscos a saúde humana e agrega valor ao produto final.

\subsection{Identificação dos custos e despesas variáveis e apuração da margem de contribuição}

No processo produtivo do caulim, após a extração nas jazidas, o material já na indústria é colocado manualmente no secador. Posteriormente, o material passa por um elevador que o leva até um depósito fechado onde há uma abertura que puxa o caulim e o conduz para os moinhos, que são responsáveis pela moagem do caulim já seco, em 
Margem de contribuição como Instrumento de Gestão: Aplicação em uma indústria de extração e beneficiamento de minérios.

Daniel Bartz, Ingrid Pereira Fanfa, Vinícius Costa da Silva Zonatto, Rodrigo da Silveira Kappel

média com $1 \%$ de umidade. Os moinhos são regulados conforme a granometria (malha) prevista.

Na empresa pesquisada, o caulim rosa moído seco (malhar 140) é produzido em maior quantidade, pois é o mais vendido e o que gera menores custos de produção por ser um produto mais grosso. O moinho de caulim pode atingir até a malha 400 , que é um produto extremamente fino, o que, conseqüentemente, requer maior tempo produtivo e gera um custo maior, o que reflete em um volume de produção e vendas menor.

O secador e os moinhos são movimentados por meio de motores elétricos. Para a mensuração do custo com a energia elétrica correspondente a cada motor e sua conseqüente alocação ao moinho correspondente, a empresa conta com os serviços de um engenheiro industrial. O Quadro 1 apresenta a distribuição dos motores e respectivas potências em unidade de força denominada cavalos (CV).

\begin{tabular}{|c|c|c|c|c|c|}
\hline \multicolumn{3}{|c|}{ Secador } & \multicolumn{3}{|c|}{ Moinho Calmag } \\
\hline $\begin{array}{l}\text { Quantidade } \\
\text { de motores }\end{array}$ & $\begin{array}{l}\text { Potência } \\
\text { individual }\end{array}$ & Equipamento & $\begin{array}{l}\text { Quantidade } \\
\text { de motores }\end{array}$ & $\begin{array}{l}\text { Potência } \\
\text { individual }\end{array}$ & Equipamento \\
\hline 01 & $30 \mathrm{CV}$ & Exaustor & 01 & $75 \mathrm{CV}$ & Moinho \\
\hline 04 & $15 \mathrm{CV}$ & Secador & 01 & $50 \mathrm{CV}$ & Exaustor \\
\hline 02 & $05 \mathrm{CV}$ & Elevador & 01 & $05 \mathrm{CV}$ & Separador \\
\hline 01 & $04 \mathrm{CV}$ & Alimentador & 02 & $04 \mathrm{CV}$ & Alimentador \\
\hline 02 & $02 \mathrm{CV}$ & Calha/correia & 04 & $02 \mathrm{CV}$ & Calha/correia caracol \\
\hline \multicolumn{2}{|c|}{ Potencia total $\rightarrow$} & $108 \mathrm{CV}$ & \multirow{2}{*}{\multicolumn{2}{|c|}{$\begin{array}{c}\text { Potencia total } \rightarrow \\
\text { Moinho P1 Re }\end{array}$}} & $146 \mathrm{CV}$ \\
\hline \multicolumn{3}{|c|}{ Moinho P2 } & \multicolumn{2}{|c|}{ Moinho P1 Resíduo Calmag } & \\
\hline $\begin{array}{l}\text { Quantidade } \\
\text { de motores }\end{array}$ & $\begin{array}{l}\text { Potência } \\
\text { individual }\end{array}$ & Equipamento & $\begin{array}{l}\text { Quantidade } \\
\text { de motores }\end{array}$ & $\begin{array}{l}\text { Potência } \\
\text { individual }\end{array}$ & Equipamento \\
\hline 01 & $75 \mathrm{CV}$ & Motor moinho & 01 & $20 \mathrm{CV}$ & Motor moinho \\
\hline 02 & $04 \mathrm{CV}$ & Caracol & 03 & $04 \mathrm{CV}$ & Ensacadeira caracol \\
\hline 01 & $05 \mathrm{CV}$ & Elevador & 01 & $05 \mathrm{CV}$ & Elevador \\
\hline 02 & $02 \mathrm{CV}$ & Calha/correia & 01 & $02 \mathrm{CV}$ & Caracol \\
\hline \multicolumn{2}{|c|}{ Potencia total $\rightarrow$} & $92 \mathrm{CV}$ & \multicolumn{2}{|c|}{ Potencia total $\rightarrow$} & $39 \mathrm{CV}$ \\
\hline \multicolumn{3}{|c|}{ Caulim Branco } & \multicolumn{3}{|c|}{ Sistema de Captação de Pó } \\
\hline $\begin{array}{l}\text { Quantidade } \\
\text { de motores }\end{array}$ & $\begin{array}{l}\text { Potência } \\
\text { individual }\end{array}$ & Equipamento & $\begin{array}{l}\text { Quantidade } \\
\text { de motores }\end{array}$ & $\begin{array}{l}\text { Potência } \\
\text { individual }\end{array}$ & Equipamento \\
\hline 01 & $03 \mathrm{CV}$ & Caracol & 01 & $01 \mathrm{CV}$ & Válvula automática \\
\hline 01 & $05 \mathrm{CV}$ & Caracol & 01 & $01 \mathrm{CV}$ & Exaustor \\
\hline \multicolumn{2}{|c|}{ Potencia total $\rightarrow$} & $08 \mathrm{CV}$ & \multicolumn{2}{|c|}{ Potencia total $\rightarrow$} & $02 \mathrm{CV}$ \\
\hline & & - & $\mathrm{Wh}=\mathrm{C}$ & $46 / 1$ & \\
\hline
\end{tabular}

Quadro 1 - Relação de motores utilizados na indústria Fonte: dados da empresa (2012). 
Margem de contribuição como Instrumento de Gestão: Aplicação em uma indústria de extração e beneficiamento de minérios. Daniel Bartz, Ingrid Pereira Fanfa, Vinícius Costa da Silva Zonatto, Rodrigo da Silveira Kappel

As informações apresentadas no Quadro 1 são essenciais para que a área de custos da empresa possa identificar e alocar a cada produto os custos diretos com energia elétrica. Para fins de cálculos dos custos com energia elétrica, a potência dos motores em CV deve ser convertida em kWh, que é a medida utilizada pelos relógios das caixas de distribuição de energia. Os dados do consumo de energia elétrica mostram que o valor gasto em cada processo produtivo é bastante baixo.

Os moinhos são utilizados para o processamento de diferentes tipos de caulim e cada um tem sua especificidade e capacidade produtiva. Neles é realizada a moagem do caulim seco, em que são utilizadas diferentes malhas conforme o tipo de produto a ser processado. O Quadro 2 apresenta uma síntese dos resultados obtidos na pesquisa, a partir da identificação dos custos diretos de fabricação dos produtos objetos de estudo. 
Margem de contribuição como Instrumento de Gestão: Aplicação em uma indústria de extração e beneficiamento de minérios.

Daniel Bartz, Ingrid Pereira Fanfa, Vinícius Costa da Silva Zonatto, Rodrigo da Silveira Kappel

\begin{tabular}{|c|c|c|}
\hline \multicolumn{3}{|c|}{$\begin{array}{c}\text { Produto: CAULIM EXTRA FINO } \\
\text { Moinho: CALMAG }\end{array}$} \\
\hline Processo & Itens & $\begin{array}{c}\text { Custo } \\
\text { em R\$ } \\
\text { p/tonelad } \\
\text { a }\end{array}$ \\
\hline \multirow{7}{*}{ Moagem } & Energia elétrica & 24,35 \\
\hline & $\begin{array}{l}\begin{array}{l}\text { Sistema de captação de } \\
\text { pó }\end{array} \\
\end{array}$ & 0,32 \\
\hline & Martelos & 1,89 \\
\hline & Acoplamentos & 1,73 \\
\hline & Grelhas & 41,06 \\
\hline & Mão-de-obra & 6,96 \\
\hline & TOTAL DA MOAGEM & 76,31 \\
\hline \multirow{11}{*}{$\begin{array}{c}\text { Embalagem } \\
\text { e } \\
\text { Carregamen } \\
\text { to }\end{array}$} & Pallet & 6,21 \\
\hline & Etiquetas & 1,23 \\
\hline & Fita & 0,82 \\
\hline & Selos & 0,45 \\
\hline & Filme plástico & 3,91 \\
\hline & Empilhadeira & 0,26 \\
\hline & \begin{tabular}{|ll} 
Depreciação & da \\
empilhadeira
\end{tabular} & 1,86 \\
\hline & Sacos de papel (sacaria) & 36,77 \\
\hline & Big Bag & 23,36 \\
\hline & TOTAL EM SACARIA & 51,51 \\
\hline & TOTAL EM BIG BAG & 25,48 \\
\hline
\end{tabular}

\begin{tabular}{|c|c|c|}
\hline \multicolumn{3}{|c|}{$\begin{array}{l}\text { Produto: CAULIM MOÍDO SECO } \\
\text { Moinho: P2 }\end{array}$} \\
\hline Processo & Itens & $\begin{array}{c}\text { Custo } \\
\text { em R\$ } \\
\text { p/tonelad } \\
\text { a }\end{array}$ \\
\hline \multirow{8}{*}{ Moagem } & Energia elétrica & 4,60 \\
\hline & $\begin{array}{l}\text { Sistema de captação de } \\
\text { pó }\end{array}$ & 0,10 \\
\hline & \begin{tabular}{|lll}
$\begin{array}{l}\text { Moinho } \\
\text { calmag) }\end{array}$ & P1 & (resíduo \\
\end{tabular} & 1,95 \\
\hline & Martelos & 0,57 \\
\hline & Acoplamentos & 0,52 \\
\hline & Grelhas & 0,42 \\
\hline & Mão-de-obra & 2,09 \\
\hline & TOTAL DA MOAGEM & 10,25 \\
\hline \multirow{11}{*}{$\begin{array}{c}\text { Embalagem } \\
\text { e } \\
\text { Carregament } \\
0\end{array}$} & Pallet & 6,21 \\
\hline & Etiquetas & 1,23 \\
\hline & Fita & 0,82 \\
\hline & Selos & 0,45 \\
\hline & Filme plástico & 3,91 \\
\hline & Empilhadeira & 0,26 \\
\hline & $\begin{array}{ll}\begin{array}{l}\text { Depreciação } \\
\text { empilhadeira }\end{array} & \mathrm{da} \\
\end{array}$ & 1,86 \\
\hline & Sacos de papel (sacaria) & 30,34 \\
\hline & Big Bag & 23,36 \\
\hline & TOTAL EM SACARIA & 45,08 \\
\hline & TOTAL EM BIG BAG & 25,48 \\
\hline
\end{tabular}

Quadro 2 - Composição parcial do custo de produção do Caulim Extra Fino e Caulim Moído Seco Fonte: dados da empresa (2012).

Os dados evidenciados no Quadro 2 são oriundos do setor de custos da empresa, que dispõe de um controle detalhado e bastante informativo de como os valores são encontrados. Tais informações são utilizadas pela empresa na contabilização dos custos de fabricação dos produtos extraídos e beneficiados pela organização. Isso mostra que a empresa pesquisada está atenta ao controle dos custos dos produtos fabricados e utiliza a contabilidade de custos como um instrumento de 
Margem de contribuição como Instrumento de Gestão: Aplicação em uma indústria de extração e beneficiamento de minérios.

Daniel Bartz, Ingrid Pereira Fanfa, Vinícius Costa da Silva Zonatto, Rodrigo da Silveira Kappel

gestão, o que pode proporcionar grandes benefícios aos gestores no gerenciamento de suas atividades operacionais.

Os resultados encontrados mostram que o processo de embalagem dos produtos fabricados pela empresa possui dois tipos de acondicionamento. Um é em sacos de papel (sacaria), sendo que para embalar uma tonelada de produto são necessários entre 30 e 40 sacos, dependendo do tipo de produto. Nesse caso, outros materiais são necessários para o acondicionamento, os quais estão identificados e mensurados no Quadro 2. O outro tipo é o Big Bag, que é um tipo de embalagem com custo menor, sendo necessária uma unidade para cada 1,5 toneladas de produto. $A$ formação do custo dessa embalagem requer somente a mensuração do custo de um Bag novo agregado ao custo da empilhadeira e de sua depreciação, pois não utiliza os demais materiais da embalagem em sacos.

Outro aspecto a ser destacado, quando se analisam as informações relacionadas aos custos parciais de produção, identificados no Quadro 2, é que o custo do processo de moagem por tonelada de caulim extra fino é expressivamente superior ao de caulim moído seco. Isso ocorre devido ao caulim extra fino requerer mais tempo de mão-de-obra, maior consumo de energia elétrica, por ser um processo mais demorado, e pelo custo das grelhas.

De posse dos custos variáveis dos produtos objeto de estudo e conhecendo-se os preços de venda praticados pela empresa, a seguir, apresenta-se o cálculo da margem de contribuição destes produtos, utilizando-se o método de custeio variável. Os resultados são apresentados na Tabela 1. 
Margem de contribuição como Instrumento de Gestão: Aplicação em uma indústria de extração e beneficiamento de minérios. Daniel Bartz, Ingrid Pereira Fanfa, Vinícius Costa da Silva Zonatto, Rodrigo da Silveira Kappel

Tabela 1 - Demonstração do cálculo da margem de contribuição por produto

\begin{tabular}{|c|c|c|c|c|c|c|c|c|c|}
\hline Itens & CBS & CRS & $\begin{array}{c}\text { CBEF } \\
\text { BB }\end{array}$ & CBEF & $\begin{array}{c}\text { CREF } \\
\text { BB }\end{array}$ & CREF & CBMS & $\begin{array}{c}\text { CRMS } \\
\text { BB }\end{array}$ & CRMS \\
\hline [1] Preço de Venda & 168,95 & 96,90 & 746,63 & 746,63 & 373,94 & 373,94 & 405,00 & 120,50 & 150,32 \\
\hline Matéria-prima & 24,85 & & 24,85 & 24,85 & & & 24,85 & & \\
\hline Extração & 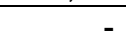 & 0,32 & - & - & 0,32 & 0,32 & & 0,32 & 0,32 \\
\hline Superficiários & - & 1,75 & - & - & 1,75 & 1,75 & - & 1,75 & 1,75 \\
\hline Transporte da mina & - & 1,06 & - & - & 1,06 & 1,06 & - & 1,06 & 1,06 \\
\hline Remonte 966C & - & 0,30 & - & - & 0,30 & 0,30 & - & 0,30 & 0,30 \\
\hline Secagem & 24,14 & 26,52 & 24,14 & 24,14 & 26,52 & 26,52 & 24,14 & 26,52 & 26,52 \\
\hline Moagem & & - & 76,31 & 76,31 & 76,31 & 76,31 & 10,25 & 10,25 & 10,25 \\
\hline $\begin{array}{l}\text { Embalagem e } \\
\text { carregamento }\end{array}$ & - & - & 25,48 & 51,51 & 25,48 & 51,51 & 45,08 & 25,48 & 45,08 \\
\hline SUBTOTAL 1 & 48,99 & 29,95 & 150,78 & 176,81 & 131,74 & 157,77 & 104,32 & 65,68 & 85,28 \\
\hline PIS & 0,32 & 0,20 & 0,98 & 1,16 & 0,86 & 1,03 & 0,68 & 0,42 & 0,56 \\
\hline COFINS & 1,47 & 0,89 & 4,52 & 5,30 & 3,95 & 4,73 & 3,13 & 1,98 & 2,56 \\
\hline ICMS & 8,32 & 5,09 & 25,63 & 30,05 & 22,40 & 26,82 & 17,73 & 7,88 & 10,24 \\
\hline CFE & 0,98 & 0,60 & 3,02 & 3,54 & 2,63 & 3,16 & 2,09 & 1,32 & 1,70 \\
\hline FGTS & 0,19 & 0,19 & 0,19 & 0,19 & 0,19 & 0,19 & 0,19 & 0,19 & 0,19 \\
\hline SUBTOTAL 2 & 11,28 & 6,97 & 34,34 & 40,24 & 30,03 & 35,93 & 23,82 & 11,79 & 15,25 \\
\hline [2] Custo Variável & 60,27 & 36,92 & 185,12 & 217,05 & 161,77 & 193,70 & 128,14 & 77,47 & 100,53 \\
\hline $\begin{array}{l}\text { [3] Margem de } \\
\text { Contribuição }(1-2)\end{array}$ & 108,68 & 59,98 & 561,51 & 529,58 & 212,17 & 180,24 & 276,86 & 43,03 & 49,79 \\
\hline Legenda & \multicolumn{9}{|c|}{$\begin{array}{cc}\text { CBS }=\text { Caulim branco seco } & \text { CBEFBB }=\text { Caulim branco extra fino big } \\
\text { bRS = Caulim rosa seco } & \text { CBEF = Caulim branco extra fino } \\
\text { CREF = Caulim rosa extra fino } & \text { CREFBB = Caulim rosa extra fino big bag } \\
\text { CBMS = Caulim branco moído seco } & \begin{array}{c}\text { CRMSBB }=\text { Caulim rosa moído seco big } \\
\text { bag }\end{array} \\
\text { CRMS = Caulim rosa moído seco }\end{array}$} \\
\hline
\end{tabular}

Fonte: dados da pesquisa (2012).

Analisando-se os dados constantes na Tabela 1, pode-se afirmar que os produtos com maior preço de venda da empresa e que geram a maior margem de contribuição são o caulim branco extra fino e o caulim branco moído seco. Os resultados da pesquisa mostram que devido à dificuldade de encontrar jazidas com caulim branco na região de atuação da empresa e a boa demanda por esse produto, o seu preço de venda é significativamente superior aos demais. Embora a procura pelo caulim branco seja expressiva, por vezes a empresa encontra dificuldades em comercializá-lo pelo preço que vem praticando. Constatou-se que o caulim branco, além da extração das jazidas da empresa, também é adquirido in natura junto a terceiros e somente beneficiado. Por sua vez o caulim rosa é extraído e beneficiado pela empresa. 
Margem de contribuição como Instrumento de Gestão: Aplicação em uma indústria de extração e beneficiamento de minérios. Daniel Bartz, Ingrid Pereira Fanfa, Vinícius Costa da Silva Zonatto, Rodrigo da Silveira Kappel

Os resultados da pesquisa mostram que os custos de extração e beneficiamento do caulim são relativamente baixos se comparados com os preços de venda praticados pela organização. Dentre os processos desenvolvidos pela indústria, o que mais gera custo é a moagem do caulim extra fino, devido a características de tempo e equipamentos necessários para sua produção, e também tem um valor representativo na composição do custo o processo de secagem.

Um aspecto a ser destacado é o significativo valor da margem de contribuição dos produtos, que é favorecida pelo preço de venda que a empresa consegue praticar. Os resultados encontrados sugerem que ao utilizar a margem de contribuição para fins gerenciais, a empresa poderá tomar decisões que poderão conduzi-la à maximização de seu lucro. Nesta perspectiva, entende-se que a empresa pesquisada poderá, por exemplo, encontrar alternativas para sanear algumas dificuldades que possui como a comercialização do caulim rosa moído seco, com aplicação em rações, que têm sua maior clientela na região de São Paulo e um grande potencial de vendas. Porém, devido aos altos custos de frete, os clientes deixam de comprar freqüentemente este produto.

Essas decisões são no sentido de: a) estimular um maior volume de vendas dos produtos que gerem maior margem de contribuição a partir da adoção de medidas que equacionem a questão do alto preço versus demanda; b) utilizar estratégias de formação de preço que considerem elementos potencializadores do incremento de vendas, otimizando os resultados gerados pelo mix de produtos; c) realizar estudos geológicos na região de atuação para tentar identificar áreas que possuam maior quantidade de caulim branco, o que poderia propiciar uma maior produção que aliada à possibilidade de fixar um preço menor teria potencial de aumentar consideravelmente 0 volume de vendas e maximizar lucros; dentre outras.

\section{CONSIDERAÇÕES FINAIS E RECOMENDAÇÕES PARA ESTUDOS FUTUROS}

O estudo proposto teve como objetivo central analisar a margem de contribuição de uma empresa que desenvolve atividades ligadas à extração e ao beneficiamento de 
Margem de contribuição como Instrumento de Gestão: Aplicação em uma indústria de extração e beneficiamento de minérios.

Daniel Bartz, Ingrid Pereira Fanfa, Vinícius Costa da Silva Zonatto, Rodrigo da Silveira Kappel

minérios e sua contribuição para a tomada de decisão, utilizando-se o método de custeio variável. Até o momento da realização da pesquisa, a empresa não utilizava esta análise em seu processo decisório.

Por meio deste estudo pôde-se constatar que o preço de venda é um elemento importante para a determinação do nível de demanda dos produtos, mas também há uma forte influência para a gestão da empresa, em especial quando se trata da análise da margem de contribuição e das decisões gerenciais que este pode influenciar. A partir dos resultados encontrados na pesquisa, pode-se inferir que a empresa analisada tende cada vez mais a aprimorar a qualidade de seus produtos, buscando alcançar esse fator como seu diferencial competitivo frente à concorrência.

Devido a sua unidade fabril estar situada no interior do Estado do Rio Grande do Sul, a empresa muitas vezes é penalizada em algumas negociações com clientes do centro do País, por questões logísticas, em função do acréscimo dos seus custos de comercialização. Assim sendo, por meio da qualidade do produto e da análise de sua margem de contribuição, a empresa pesquisada poderá manter um equilíbrio em suas operações de modo a desenvolver ações com vistas a ampliar o seu volume de vendas e maximizar seus resultados.

Mediante a análise da margem de contribuição dos produtos fabricados pela empresa, torna-se possível avaliar o detalhamento dos custos diretos de fabricação por produto e sua rentabilidade, identificando oportunidades de melhoria na formação do preço de venda ou na absorção de custos adicionais, como os custos de transporte, decorrentes da comercialização destes produtos há diferentes centros, que em determinadas ocasiões inviabilizam a comercialização dos produtos da empresa. Tais ações podem contribuir com a organização no incremento das vendas e no aumento da lucratividade da empresa.

Conclui-se que a utilização da margem de contribuição como instrumento de análise e de apoio ao processo decisório poderá contribuir significativamente para a avaliação das práticas gerenciais atuais da empresa e instigar seus gestores a refletir sobre a validade da gestão estratégica de custos. A avaliação detalhada da margem de contribuição pode contribuir ainda no sentido de motivar os gestores a realizar uma 
Margem de contribuição como Instrumento de Gestão: Aplicação em uma indústria de extração e beneficiamento de minérios.

Daniel Bartz, Ingrid Pereira Fanfa, Vinícius Costa da Silva Zonatto, Rodrigo da Silveira Kappel

reavaliação dos preços de venda dos produtos, como forma de alavancar o volume de vendas, haja vista a margem de contribuição identificada pela pesquisa apresentar uma condição bastante favorável. Em conseqüência disso, poderia ocorrer aumento do faturamento da empresa pelo maior volume de vendas, o que culminaria com melhores resultados.

Por fim, pode-se afirmar que o estudo foi de grande importância para a empresa pesquisada, pois diagnosticou elementos pertinentes a gestão de custos e evidenciou a margem de contribuição de seus produtos, permitindo aos gestores tomar decisões mais acertadas e com menor nível de incertezas. Essas decisões poderão vir a contribuir para a maximização dos resultados da empresa, sendo essencial para decisões de curto prazo, principalmente relacionadas à possibilidade de redução de custos.

Para futuros estudos recomenda-se a abordagem das estratégias de formação do preço de venda e o efeito sobre a margem de contribuição, bem como a identificação de um custo-padrão e de uma margem de contribuição padrão, como instrumentos de apoio ao processo decisório. Dessa forma, novos elementos da gestão estratégica de custos poderiam ser discutidos de forma teórica e empiricamente aplicados a uma realidade empresarial.

\section{REFERÊNCIAS}

BORNIA, A. C. (2002). Análise Gerencial de Custos. Porto Alegre: Bookman.

BRUNI, A. L.; FAMÁ, R. (2004). Gestão de custos e formação de preços. São Paulo: Atlas.

CARVALHO JUNIOR, C. V. O.; BRUNI, A. L.; PAIXÃO, R. B.; OLIVEIRA FILHO, N. F. (2009). Uso da margem de contribuição em controladoria: um estudo de caso em empresa de transporte urbano de passageiro. Revista de Contabilidade do Mestrado em Ciências Contábeis da UERJ, v. 14, n. 2, p. 02-17.

CAVENAGHI, V. (1996). O Modelo de Gestão Econômica (GECON) aplicado à área de produção. Caderno de Estudos. São Paulo, FIPECAFI, n. 14, p. 1-30, jul./dez.

GIL, A. C. (1996). Como elaborar projetos de pesquisa. (3 ed.). São Paulo: Atlas. 
Margem de contribuição como Instrumento de Gestão: Aplicação em uma indústria de extração e beneficiamento de minérios. Daniel Bartz, Ingrid Pereira Fanfa, Vinícius Costa da Silva Zonatto, Rodrigo da Silveira Kappel

HANSEN, D. R.; MOWEN, M. M. (2001). Gestão de custos: contabilidade e controle. São Paulo: Pioneira.

HENDRIKSEN, E. S.; VAN BREDA, M. F. (1999). Teoria da contabilidade. São Paulo: Atlas.

HORNGREN, C. T. (2000). Contabilidade de custos. Rio de Janeiro: Livros Técnicos e Científicos.

; SUNDEM, G. L.; STRATTON, W. (2004). Contabilidade gerencial. (12 ed.). São Paulo: Prentice-Hall.

IUDÍCIBUS, S.; MARION, J. C. (2000). Curso de contabilidade para não contadores. 3. ed. São Paulo: Atlas.

; MARTINS, E.; GELBCKE, E. R. (2006). Manual de Contabilidade das Sociedades por Ações. (7 ed.). São Paulo: Atlas.

LEONE, G. (1997). Curso de contabilidade de custos. São Paulo: Atlas.

. (2000). Curso de contabilidade de custos. (2 ed.). São Paulo: Atlas.

. (2001). Custos: um enfoque administrativo. (14 ed.). Rio de Janeiro: FGV.

MAHER, M. (2001). Contabilidade de custos: criando valor para a administração. São Paulo: Atlas.

MARTINS, E. (1998). Contabilidade de Custos. (6 ed.). São Paulo: Altas.

. (2003). Contabilidade de custos. (9 ed.). São Paulo: Atlas.

MEGLIORINI, E. (2003). Análise crítica dos conceitos de mensuração utilizados por empresas brasileiras produtoras de bens de capital sob encomenda. 213 fls. (Tese de Doutorado). Universidade de São Paulo - USP, São Paulo.

. (2007). Custos: análise e gestão. (2 ed.). São Paulo: Pearson.

RAUPP, F. M.; BEUREN, I. M. (Org.). (2003). Metodologia da pesquisa aplicável às ciências sociais. In: Como elaborar trabalhos monográficos em contabilidade: teoria e prática. São Paulo: Atlas.

SANTOS, J. J. (1987). Análise de custos: um enfoque gerencial. São Paulo: Atlas. 
Margem de contribuição como Instrumento de Gestão: Aplicação em uma indústria de extração e beneficiamento de minérios. Daniel Bartz, Ingrid Pereira Fanfa, Vinícius Costa da Silva Zonatto, Rodrigo da Silveira Kappel

SHANK, J.; GOVINDARAJAN, V. (1997). A revolução dos custos. (6 ed.). Rio de Janeiro: Campus.

WERNKE, R. (2004). Gestão de Custos. (2 ed.). São Paulo: Atlas.

Data de Submissão: 17/09/2010

Data de Aceite: 03/07/2012 